\title{
Behavioural responses to neighbourhood reputations
}

\author{
Matthieu Permentier • Maarten van Ham • \\ Gideon Bolt
}

Published online: 3 July 2007

(C) Springer Science+Business Media B.V. 2007

\begin{abstract}
Most research on the effect of neighbourhood reputations focuses on the influence on attitudes and behaviour of non-residents. Much less attention is paid to the possible effects of a poor neighbourhood reputation on behaviour of residents. In order to get a better understanding of the effect of neighbourhoods on its residents (the so-called neighbourhood effects) and the role of neighbourhoods in the urban housing market, it is necessary to fill this gap. The aim of this paper is to review the literature on the reputation of places and to give an overview of possible behavioural responses of residents to negative neighbourhood reputations. The paper develops a model of behavioural responses of residents based on Hirschman's 'Exit, Voice and Loyalty' framework. Three basic responses are central to the discussion of the literature: leaving the neighbourhood, attempting to improve the neighbourhood through neighbourhood participation, and (dis)investing in social contacts within the neighbourhood.
\end{abstract}

Keywords Neighbourhoods - Reputations - Residents - Behavioural responses · Residential mobility · Neighbourhood participation · Social contacts

\footnotetext{
M. Permentier $(\bowtie) \cdot$ G. Bolt

Urban and Regional Research Centre Utrecht (URU), Utrecht University, P.O. Box 80115, Utrecht 3508 TC, The Netherlands

e-mail: m.permentier@geo.uu.nl

G. Bolt

e-mail: g.bolt@geo.uu.nl

M. van Ham

Centre for Housing Research (CHR), School of Geography \& Geosciences,

University of St Andrews, Irvine Building, North Street, St Andrews,

Fife KY16 9AL, UK

e-mail: maarten.vanham@st-andrews.ac.uk
} 


\section{Introduction}

There is renewed interest in urban neighbourhoods among policy-makers and the scientific community (Kearns and Parkes 2003). Although it is widely acknowledged that the neighbourhood is no longer the centre of daily life for most residents, there is the strong belief that the neighbourhood context plays an important role in a wide variety of social outcomes for residents. These so-called neighbourhood effects are thought to occur in (mostly deprived) neighbourhoods where low-income groups and immigrants are concentrated (see for reviews on the neighbourhood effects discussion Ellen and Turner 1997; Van Kempen 1997; Friedrichs 1998; Leventhal and Brooks-Gunn 2000; Dietz 2002; Sampson et al. 2002; Galster 2005). Research has shown that, for example, living in concentration neighbourhoods has an effect on individual labour market outcomes (Wilson 1987), educational achievements (Overman 2002), deviant behaviour (Friedrichs and Blasius 2003), social exclusion (Buck 2001) and social mobility (Musterd et al. 2003). Most neighbourhood effects have been found in (highly segregated) American neighbourhoods, while European studies (for example in the Netherlands) show more modest, though still significant effects of the neighbourhood context on residents (Musterd et al. 2003; Galster 2005).

The relevant literature on neighbourhood effects distinguishes three categories of effects: endogenous effects, exogenous effects and correlated effects (Manski 1993; Buck 2001). Endogenous effects arise when the behaviour of neighbourhood residents has a direct influence on other residents (Galster 2005). The theories that are most widely adopted in the neighbourhood effects literature (like socialisation, epidemic and social network theories) are part of this category (Wilson 1987; Ellen and Turner 1997). Exogenous effects arise when behaviour and attitudes of one individual depend on the (exogenous) characteristics of neighbourhood residents. An example of this category is the recent immigrant who feels special comfort thanks to the proximity to others with the same national background (Galster 2005). Finally, correlated effects arise when individuals in the same neighbourhood behave similarly because they face similar institutional environments or have similar individual characteristics. Stigmatisation of individuals by externals on the basis of the reputation of their neighbourhood is one particular correlated effect (Andersson and Musterd 2005). Most research on this topic examines the material and psychological disadvantages of living in a neighbourhood with a poor reputation (see for example Bauder 2002; Hastings and Dean 2003). It is argued that the chances for social participation of people residing in neighbourhoods with a poor reputation, are limited due to the bad name their neighbourhood has (Wacquant 1993; Van Kempen 1997; Bauder 2001, 2002). Jobs are not offered to them (Wilson 1996); people do not receive mortgages from banks, or only under disadvantageous conditions (Aalbers 2005) and people's self-esteem can be damaged by living in a notorious area (Wacquant 1993; Taylor 1998; Dean and Hastings 2000).

Although the material and psychological disadvantages of living in a neighbourhood with a poor reputation have been widely studied, relatively little attention has been given to the effect that the reputation of these neighbourhoods has on the behaviour of neighbourhood residents. The term "behaviour', in this article refers 
to purposeful actions taken by self-interested individuals to improve or maintain the quality of their lives. Thus, material and psychological consequences are about what happens to people (it is not the decision of a resident to be discriminated against or to lose self-esteem), while behavioural consequences refer to the actions that people take as a result of a bad (or declining) reputation.

Several behavioural responses to a neighbourhood's poor reputation can be expected. Leaving the neighbourhood is probably among the most important ones (Rossi 1955; Kearns and Parkes 2003; Clark et al. 2006). Other literature suggests that a poor neighbourhood reputation can have an effect on participation and social contacts. Two directions can be discerned. Some argue that a negative neighbourhood reputation can have a harmful effect upon social contacts and participation (see for example Wacquant 1993), while others (Mazanti and Pløger 2003) suggest a positive effect on the mutual relations between residents and their organisational capacities. More knowledge about the effect that the reputation of neighbourhoods has on residents' behaviour can help us understand the role of the neighbourhood in residential mobility behaviour more clearly. It can also add to the understanding of one particular mechanism behind neighbourhood effects.

Unfortunately, there is no ready-to-use theory that would help us understand the relation between reputation and behavioural responses. An important starting point for such a theory is the Exit, Voice and Loyalty framework (EVL), which was developed by Hirschman (1970) and expanded by others (Rusbult et al. 1982; Farell 1983). The framework was originally developed to study the responses of consumers to products that show a decline in quality, but it can also be used to expound the possible behavioural responses to a poor neighbourhood reputation.

The main aim of this article is to offer, on the basis of an overview of the literature, more insight into the relationship between neighbourhood reputation and behaviour of residents. Further, by applying the EVL framework we aim to provide more insight in the interrelatedness of the several behavioural responses. This may help bridge the gap between the bodies of literature that focus on only part of the response options: the residential choice literature (exit) and the literature on social capital and civic participation (voice and loyalty).

\section{The concept of reputation}

\subsection{A definition of reputation}

People constantly form opinions without always being aware of it. Reputations can be attached to multiple objects, varying from companies to celebrities. An important characteristic of the term reputation is that it refers to "The beliefs or opinions that are generally held about someone or something" or "A widespread belief that someone or something has a particular characteristic" (Oxford Dictionary 2004).

Places are no exception to the labelling process: people attach a reputation to most countries, states, cities or neighbourhoods. One of the first authors in the field of sociology and geography to deal with the concept of neighbourhood reputations was Walter Firey. His 1945 article on Bostonian neighbourhoods uses a subjective 
understanding of the city in which symbolism and sentiments received a central role. He recognised that a spatial area can act as a "a symbol for certain cultural values that have become associated with it" (Firey 1945, p. 140). Firey's example of Beacon Hill, a residential area near the centre of Boston, illustrates that neighbourhoods can retain their position in the urban hierarchy by operating as a symbol for certain (as in the case of Beacon Hill, historic and aesthetic) values: in other words, the area has a certain reputation (cf. Hunter 1974).

Although the concept of reputation has been applied to neighbourhoods, very few social scientists give an explicit definition of the reputation concept. Hortulanus (1995, p. 42) is an exception. He argues that the neighbourhood is "a mirror and symbol of the position a household occupies in society, its preferences and life style. The neighbourhood is thus a representation factor. Reputation refers thus to the meaning and assessment assigned by residents and outsiders to the neighbourhood. Next, it refers more or less to the steady image the neighbourhood has among city residents and to the place it has in that way in the urban neighbourhood hierarchy.', Hortulanus (1995) argues that the concept of reputation has a more neutral sound than stigma or image. In the time since the term stigma was defined by Goffman (1963) as a spoiled social identity, it has taken on a negative association and has come to represent an anomaly, deviating from individual characteristics and behaviour assessed ordinary and acceptable by society (Harvey 2001). So while a stigma is always negative, reputations can also be good.

In the literature, the concept of reputation is related to the concept of status. According to Marshall (1998) status arises from "the subjective evaluations of positions in a system of social stratification." Although status can also refer to the neighbourhood level, it is more often used at the individual level. A person's individual status can be derived from the (reputation of the) neighbourhood he or she lives in. This way, the neighbourhood can be used as an indicator of a person's individual status (Warner et al. 1960; Congalton 1969). A residential address can then be "considered the quickest index to family social status"' (Coleman and Neugarten 1972; Lee et al. 1994). The neighbourhood can therefore be seen as a reflection and symbol of one's position in society and preferences (Firey 1945; Hortulanus 1995; Van Kempen 1997; Van der Horst et al. 2001). Congalton (1969) sees the address as the locator of a household in social space: "So pervasive is this effect that residential location has frequently been used as one of the measures of an individual's position in the local prestige hierarchy" (see also Warner et al. 1960). The urban population assesses neighbourhoods and residential groups in a contrastive way (Suttles 1972; Semyonov and Kraus 1982; Forrest and Kearns 2001). "Residential identities [...] are embedded in a contrastive structure in which each neighborhood is known primarily as a counterpart to some of the others"' (Suttles 1972, p. 51). Not the absolute, but the relative differences are thought to be relevant in the comparisons between neighbourhoods (Suttles 1972; Hortulanus 1995; Galster 2001). The identification with a specific place automatically means identification against another place (Rose 1995, p. 92). The positioning of neighbourhoods in contrast to each other leads to a hierarchy in which the different neighbourhoods are positioned in relation to one another (Suttles 1972; Hortulanus 1995, p. 42). The reputation of a neighbourhood can be deduced from its position in this hierarchy. 


\subsection{Internal and external reputation}

Neighbourhood reputations are a product of both non-residents' and residents' perceptions. The reputation that residents hold of their neighbourhood may be denoted as internal reputation and the neighbourhood's reputation among non-residents as external reputation (Hortulanus 1995). The external and internal reputation can not been taken separately. They are likely to influence each other because of an ongoing social interaction between residents and non-residents. However, this does not imply that the internal and external reputation are congruent with each other.

The reputation among non-residents (outsiders), the external reputation, consists of simplified images of neighbourhoods expressed as sharp boundaries and exaggerated differences noted by outsiders (Suttles 1972). These boundaries are used to make the city comprehensible for daily activities (where is it safe to go?) and status considerations (what type of people live where?). The category of outsiders may have a shared view of a neighbourhood's reputation, as is found in a study that Logan and Culver (1983) carried out in New York. They found that residents of a working-class area and residents of a more affluent area gave similar ratings to 84 communities on Long Island (New York). However, there may be differences between groups of outsiders and even within one group of outsiders, as Suttles' findings in Chicago illustrate (1968, p. 25). Suttles argues that white non-residents assess West Side neighbourhoods differently than black non-residents. The first group thinks of it as another impoverished 'negro' area, while the latter contrasts it with another Afro-American area (such as the more affluent South Side). This shows that background references used in the assessed neighbourhoods might differ and can lead to a different understanding of the area.

The internal and external reputation may partially coincide, since residents and non-residents are likely to judge certain neighbourhood attributes in the same way. Curtis and Jackson (1977, p. 91) found a strong correlation between the internal reputation (rating of the neighbourhood compared to other neighbourhoods by residents) and the external reputation (the rating by interviewers of the residential areas). However, there are usually some differences between the external and the internal reputation. Firstly, residents tend to rate their neighbourhood higher than non-residents. This is partly the result of selection: people who have some choice on the housing market have selected a neighbourhood that meets their aspirations. It is therefore no wonder that they have a more positive view of their neighbourhood than non-residents (Clark and Cadwallader 1973; Bell et al. 1996). Secondly, residents without any prospect of improvement in their residential situation undergo a psychological adaptation to their situation and rate their neighbourhood higher because it is the best they can get (see Festinger 1957).

Apart from the fact that residents give their neighbourhood a higher rating, they also differ from non-residents in their ability to apply a micro-differentiation: a more refined classification of the neighbourhood at the block-face, street or even building level (Wacquant 1993; Hastings and Dean 2003; Purdy 2003). This ability to apply micro-differentiation is not only a result of superior knowledge among the residents about their neighbourhood (Evans 1980). It is also because the residents have an interest in micro-differentiations as a possible means to detach themselves 
from unwanted elements in their neighbourhood. Residents can associate with or disassociate from other parts of the neighbourhood. Residents of higher status areas within larger but lower-status communities will use micro-differentiations to emphasise the prestige of their residential environment. Residents of less prestigious areas use the same mechanism the other way around. Being identified with the more prestigious neighbourhoods is useful to them (Hunter 1974; Lee and Campbell 1997). In infamous neighbourhoods, people might apply a strategy of differentiation to detach themselves from the 'real bad parts' of the neighbourhood (Wakefield and McMullan 2005).

\section{Exploring behavioural responses to neighbourhood reputations}

In the above, it has been argued that neighbourhood reputations are constructed as a result of the continuous interaction between the way residents and non-residents perceive a neighbourhood.

Figure 1 illustrates that the behaviour of residents in a neighbourhood X (box 5) is influenced by the internal assessment of the reputation of that neighbourhood (box 6), as well by the assessment of the reputation by outsiders (those who do not live in neighbourhood $\mathrm{X}$ and professionals, box 1). As stated in the previous section, the internal and external reputations mutually influence each other to some degree. There is abundant research on the effects of the internal assessment on residents' behaviour. For instance, subjective evaluations of the neighbourhood are usually included in models on residential mobility (e.g. Lee et al. 1994; Lu 1998; Kearns and Parkes 2003), while attention to the effects of external reputation is scarce (Tsfati and Cohen 2003).

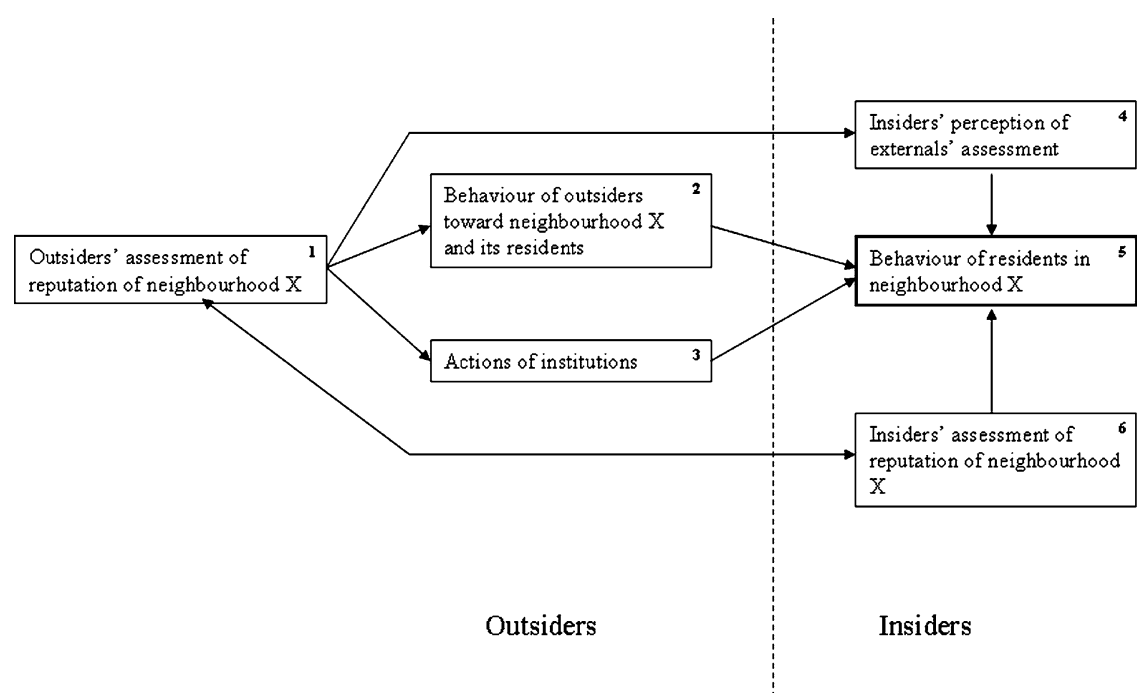

Fig. 1 Relationship between (internal and external) reputation of neighbourhood $\mathrm{X}$ and behaviour of residents of neighbourhood $\mathrm{X}$ 
The influence of the outsiders' assessments on behaviour of residents in neighbourhood $\mathrm{X}$ is mediated through three elements (box 2, box 3 and box 4), as shown in Fig. 1. The 'internals' perception of (outsiders' assessment of) reputation' (the first element, box 4) is also called self-reflective reputation by Rijpers and Smeets (1998). If residents of a neighbourhood think that externals perceive their neighbourhood as negative, this could result in a situation in which the residents disassociate themselves from their neighbourhood or adjust their behaviour towards fellow residents. Whether or not the externals actually perceive the neighbourhood as the neighbourhood residents think they do does not matter. What matters is that the residents might change their behaviour because of the perceived reputation of externals (Tsfati and Cohen 2003).

The 'actions of institutions that affect neighbourhood $\mathrm{X}$ and its residents' (box 3) and 'behaviour of outsiders toward neighbourhood X and its residents' (box 2) are respectively the second and the third element in the model. The idea is that the external assessment has an influence on the behaviour of externals (residents of other neighbourhoods as well as institutions), which in turn has an effect on the behaviour of residents.

Based on the reputation of (bad) neighbourhoods, institutions may develop strategies to deal with such neighbourhoods and their residents. A prime example is 'blocking strategies' by which actors try to prevent certain groups from stigmatised neighbourhoods entering (highly regarded up-market) urban neighbourhoods, thus avoiding changes in the neighbourhood features (Wyly 2002). Much discussion surrounds realtors who serve as gatekeepers, seeking to 'preserve' white neighbourhoods from an influx of people from stigmatised (Afro-American) areas by steering individuals from these areas to certain other parts of the city (Galster and Godfrey 2005). As a result, these blocking strategies can influence the behaviour of the residents of stigmatised neighbourhoods.

An example of 'behaviour of outsiders' is white avoidance: the decision not to move and relocate into certain areas (predominantly non-white) urban neighbourhoods with a notorious reputation among non-residents. The phenomenon of white avoidance has been extensively studied in the American context. It has been found to exert a significant influence on the racial composition of urban neighbourhoods (Clark 1991). Several studies by Clark $(1991,1992)$ have shown the preference of white Americans for predominantly white neighbourhood and the impact of this preference on racial composition of neighbourhoods. Another form of the 'behaviour of outsiders' is the disinclination to visit certain neighbourhoods. Crump (2002) mentions in this respect the attitudes and behaviour of non-residents toward inner-city districts in the United States. Due to the extremely negative reputations of these inner cities, non-residents shun these districts because they are fearful of the local (predominantly Afro-American) community.

\subsection{Residents' behavioural responses to neighbourhood reputations}

Negative neighbourhood reputations can have different consequences for neighbourhood residents and possibly lead to different responses from them. Hirschman's (1970) Exit, Voice and Loyalty framework may be useful to categorise these 
responses. It was originally developed to explain possible reactions of unsatisfied customers to products, companies or organisations.

Hirschman discerns two types of customer responses: exit and voice. The exit option is exercised when consumers stop buying a product or quit a certain organisation and possibly switch to a competing brand or organisation. Voice is the expression of dissatisfaction directed to the appropriate level of management or organisation or to anyone who cares to listen, either individually or collectively (Hirschman 1970, p. 4). Voice can be discerned in a horizontal and vertical form: horizontal voice is when a critic complains to peers, while the vertical form refers to the expression of discontent to persons who are affiliated with the specific organisation and who occupy a managerial position within that organisation (O'Donnell 1986). To illuminate why people choose either an exit or a voice response, Hirschman introduced the concept of loyalty. Loyalty can be understood as an attachment to a product or organization. As a rule, "loyalty holds exit at bay and activates voice", (Hirschman 1970, p. 79). Whereas in the work of Hirschman, loyalty is construed as a psychological state that influences the exit and voice option, other researchers (for example Lyons and Lowery 1986) later added loyalty as a third response option in the context of residential communities. That is justifiable, as loyalty to a residential community is more multifaceted than loyalty to a product. The latter (brand loyalty) merely reflects a psychological state, while the former reveals itself not only as a state of mind (psychological sense of community) but also in diverse kinds of behaviour. For instance, speaking well of the neighbourhood, strengthening social contacts within the neighbourhood and voting are examples of actions that reflect loyalty.

Besides loyalty, neglect is regularly added as a fourth response option (see for example Rusbult et al. 1982; Farrell 1983; Lyons and Lowerty 1986). In the context of residential communities, limiting social contacts in the neighbourhood or talking negatively about the neighbourhood are examples of neglect. However, neglect should not be seen as an additional concept that extends the EVL framework, as loyalty and neglect can be considered opposite aspects of the same construct. It is not possible to choose both the loyalty and the neglect option at the same time (Dowding et al. 2000). Loyalty has a negative effect on the propensity to choose an exit option (in the future) and increases the likelihood of voice (Fig. 2). By definition, neglect increases the likelihood of exit and decreases the likelihood of voice.

Within the neighbourhood context, Van Vught et al. (2003) have used Hirschman's framework to discover which factors influence the problem-solving strategies of residents who are confronted with neighbourhood problems. Exit and voice strategies were found to be influenced by dissatisfaction with community services - the more dissatisfied community members there are, the more likely they are to take action, either by exiting or voicing their concerns, than the satisfied members (see also Lyons and Lowery 1986) - and people's dependency on the community and its services. The authors argue that exit opportunities are more limited for older people, households with children, homeowners and lower-income households, as they are more dependent on the neighbourhood (Orbell and Uno 1972). Thus, people who are dissatisfied and less dependent are more likely to take the exit option, while dissatisfied people with higher dependency on their area of residence are more likely to choose the voice option. 


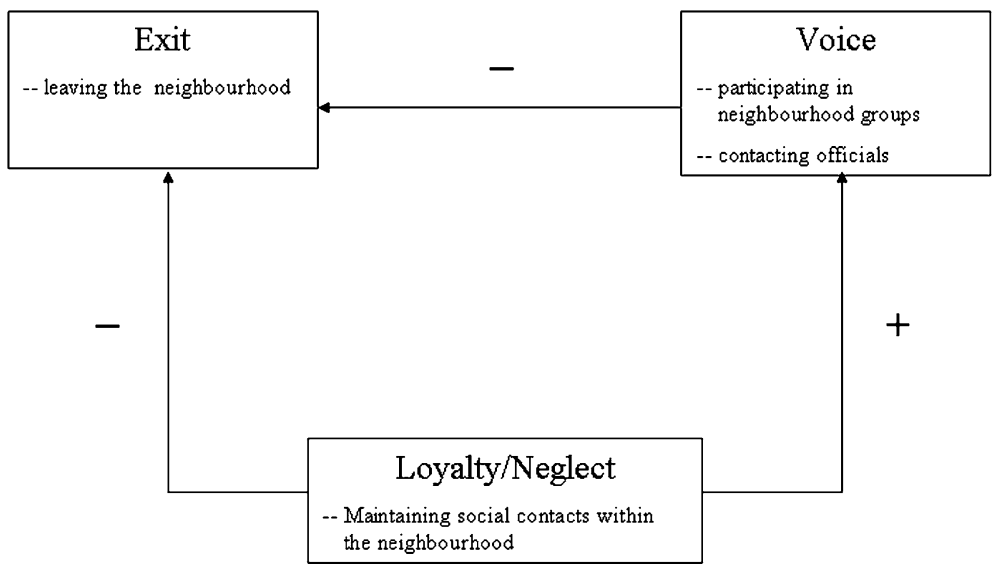

Fig. 2 Responses to dissatisfaction with the neighbourhood's reputation

Lyons and Lowery (1986) argue that prior satisfaction with community services influences the chosen strategies. Persons who were used to high-quality services in their present or former neighbourhood are more likely to be dissatisfied compared to persons who are used to the (poor) level of service offered in their current neighbourhood. Persons who were previously more satisfied with community services are more opt to use the voice option when service levels decline, while persons who were dissatisfied all the time are more likely to use the exit option. Another important aspect is the level to which individuals invest in their neighbourhood. Persons who are owner-occupants are more likely to use the voice option, while renters are more likely to choose the exit option (see Cox 1983; Van Vught et al. 2003). The voice option is also more likely to be used by persons who feel more attached to their neighbourhood.

\subsection{Neighbourhood reputation and exit}

The exit option is probably the most clear-cut behavioural response to negative neighbourhood reputations, since it is a dichotomous response: either one leaves or one stays (Dowding et al. 2000). People who live in a neighbourhood with a bad reputation and feel that the neighbourhood reputation is detrimental to their wellbeing can opt for the exit option. The residents who attach most importance to the neighbourhood's reputation can be expected to be among the first to opt for the exit option when this reputation becomes negative. This means a potential loss of active persons (Hirschman 1970, p. 51; Orbell and Uno 1972; Dowding et al. 2000). The decision to leave the neighbourhood (the exit option) is not always simple: the burden of moving can be rather high, as relocation involves high (transaction and/or emotional) costs (Dowding et al. 2000, p. 471).

Although neighbourhood reputations are likely to have a substantial impact on residential mobility (Semyonov and Kraus 1982), the literature on residential mobility seldom includes the neighbourhood's reputation as an explanatory variable. This is remarkable, as it was already acknowledged in the 1970s that 
subjective evaluation of neighbourhoods may be better in explaining spatial behaviour than supposedly objective neighbourhood data like socioeconomic status and ethnic composition (Clark and Cadwallader 1973). Although some researchers on residential mobility incorporate the subjective evaluation of neighbourhoods in their models (e.g. Lee et al. 1994; Lu 1998; Kearns and Parkes 2003), little attention has been devoted specifically to the role that a neighbourhood's reputation plays in residential mobility. The study by Tsfati and Cohen (2003) is one of the few exceptions. They found that the way residents perceive the image of their town (among externals) has an independent effect on thinking about residential mobility over and above the effect of satisfaction with the living conditions. The reasoning behind this is that the self-image of people is strongly affected by the way they believe others see them and the groups they belong to. When people believe their status suffers from membership in a certain group, they will try to disassociate themselves from that group. Of course, that is not possible when someone is stigmatised on the basis of an ascribed characteristic (like gender and race). But when someone feels stigmatised on the basis of residence, there is the possibility to disassociate from fellow residents by moving out of the neighbourhood.

\subsection{Neighbourhood reputation and voice}

The voice option indicates a person's expression of dissatisfaction with the reputation of the neighbourhood. Unlike the exit option, voice is open to various levels (Dowding et al. 2000). Dissatisfaction can be communicated by individuals, but residents can also organise themselves in neighbourhood committees. Possibly, the reputation of the neighbourhood influences the neighbourhood participation of individuals. The literature on neighbourhood participation has so far only paid limited attention to the influence of the area's reputation on participation. From the (limited) literature dealing with reputation and neighbourhood participation, there is some evidence that residents of an infamous residential area are likely to choose the voice option. Mazanti and Pløger (2003) argue on the basis of their research in Avedøre Stationsby (a stigmatised area on the outskirts of Copenhagen) that the negative reputation worked as an impulse for participation. It brought a group of residents together in "collective stance against the outside world's understanding and negative stigmatisation of their neighbourhood" (Mazanti and Pløger 2003, p. 320). To fight (what in their eyes was) undeserved stigma, the residents came closer together and organised themselves.

The findings of the aforementioned study differ from a study by Wacquant (1993). According to the latter study, residents of infamous neighbourhoods do not want to organise themselves in a neighbourhood coalition, due to the neighbourhood reputation. The possibility to mobilise residents was found to be absent. Wacquant (1998) coined the term 'organizational desertification' to describe a situation in which the residents' disorganisation renders them unable to force the local government to improve neighbourhood conditions. Marcuse (1993) argues that, as a result of this organisational desertification, stigmatised areas end up with facilities unwanted by the rest of society-like half-way houses, AIDS clinics and shelters which are refused in other areas and thus reinforce the stigma. Wacquant (2004) interprets this process as an example of the asymmetric relation of the ghetto with society. 


\subsection{Neighbourhood reputation and loyalty/neglect}

Residents who choose the loyalty option put trust in the neighbourhood and its residents. They hold positive associations about the area in which they live; residents do not mind associating themselves with their neighbourhood. Social contacts with residents are in this case not influenced by the reputation of the area.

When people choose the loyalty-option, it is not unlikely that they will choose the voice option in the future (or even simultaneously). Just like buying a house, maintaining social contacts with other residents and putting trust in them can be seen as an investment in the neighbourhood and thus as influencing whether they will choose to exit or to use their voice when problems (such as a negative neighbourhood reputation) arise. Residents who have invested extensively in the community have more to lose and are more likely to choose the voice option if the quality and/or reputation of their neighbourhood should deteriorate in the future than those with less loyalty, even if they share the same satisfaction levels (Dowding et al. 2000).

As stated in section 4.1, we do not consider neglect as a distinct response, on top of the three responses that Hirschman distinguished. Rather, we see neglect as merely the opposite of loyalty. Thus, neglect refers to behavioural responses such as avoiding social contacts within the neighbourhood, or saying bad things about the neighbourhood.

Several studies have examined the effect of an area's negative reputation on loyalty. They all point in the direction of a negative effect on loyalty and consequently a positive effect on neglect. According to Suttles (1972, p. 236), Wacquant (1993) and Brodsky (1996), disassociating oneself from the neighbourhoods' and the neighbours' bad reputation can be a motivation to undermine social relations within the neighbourhood. The costs of identification with the neighbourhood are perceived to be too high; therefore people retreat from their neighbourhood (Costa Pinto 2000). Residents emphasise that they are not part of a neighbourhood network in which mutual relations and services are maintained (see also Taylor 1998). Suttles (1968, pp. 25-26) suggests that in stigmatised areas, residents can use another strategy besides total isolation. By building intimate and deep relations with a very limited number of residents, a safe world with mutual understanding is constructed. These types of relations are likely to have a negative effect on the neighbourhood participation of residents. By employing this strategy, residents protect themselves from the negative reputation of their area of residence. This approach has some side-effects, undermining trust in fellow-residents and decreasing local social solidarity. According to Wacquant (1993), strategies of distancing reinforce the negative view of the outsiders, creating a self-fulfilling prophecy in which the public disgrace produces exactly what people think they observe: social and communal disorganisation and cultural anomaly (Wacquant 1993, p. 375). Another strategy to prevent association with the neighbourhood and its residents is making use of internal social differentiation, which leads to a categorisation of residents into those who are morally inferior and those who are not (see Wacquant 1993; Costa Pinto 2000; Hastings 2004). Some individuals and families are labelled as vile people lacking values, whereby they take on the role of scapegoat. At the 
same time, residents emphasise their own morality and may explain their presence in this area as an accident, caused by external influences (unemployment, divorce etc). This social differentiation is not only used for individuals but can also be deployed at the sub-neighbourhood, block, or flat level (so-called micro-hierarchies). In this case the stigma attached by outsiders is then reproduced on a lower scale within the home area. Some areas are said to be 'good' parts, while others are feared, possibly leading to avoidance of these areas at certain times or at all times.

\section{Conclusion}

Studies of behavioural responses to negative neighbourhood reputation can make a significant contribution to the literature on neighbourhood effects. As stated in the introduction to this paper, research on neighbourhood effects focuses on socialisation theories (or, more generally, on endogenous effects) and tends to miss the influence of the neighbourhood's reputation on the lives of people residing in notorious neighbourhoods. Some research has been done on the material and psychological consequences that a negative neighbourhood reputation can produce. However, the behavioural responses of neighbourhood residents to a negative reputation of their neighbourhood have received relatively little attention.

In the literature, we have discerned various behavioural responses to neighbourhood reputations. As a means to integrate the literature on different types of responses to negative neighbourhood reputations, we applied Hirschman's Exit, Voice and Loyalty framework. Voice and loyalty/neglect are the focus of research in community studies. In this field, aspects of loyalty (for example maintaining social contacts) are defined as social capital, while voice, i.e. participation in the neighbourhood, is seen as one of the positive effects of social capital (Putnam 2000). The exit option is the subject matter of the residential mobility literature.

Apart from a few exceptions (Orbell and Uno 1972; Cox 1983; Van Vught et al. 2003), voice and exit are studied separately. That is striking, as both options are interrelated. A deteriorating quality and/or reputation of the neighbourhood may increase the likelihood of relocation as well as the likelihood of active participation in the neighbourhood. Those who opt for the voice variant may be less likely to move out in the future, as it would make their 'investments' of no avail. The combination of insights from both community studies and residential mobility literature may especially benefit the residential mobility literature. The focus in this literature is on changes in the life cycle and labour market careers that trigger moves. When neighbourhood problems are incorporated as a reason for residential stress, actively trying to improve the neighbourhood is seldom seen as an alternative to moving (Clark et al. 2006). To move or not to move, that seems to be the only question. In this respect, the contrast to dissatisfaction with the dwelling is notable, as it is usually acknowledged that adjusting a dwelling, for instance through enlargement, is an alternative to moving (e.g. Brown and Moore 1970).

Acknowledgements We would like to thank the editors of HBE and the anonymous referees for their useful comments on an earlier version of this paper. 


\section{References}

Aalbers, M. (2005). Who's afraid of red, yellow and green? Redlining in Rotterdam. Geoforum, 36, 562-580.

Andersson, R., \& Musterd, S. (2005). Area-based policies: A critical appraisal. Tijdschrift voor Economische en Sociale Geografie, 96(4), 377-389.

Bauder, H. (2001). 'You're good with your hands, why don't you become an auto mechanic': Neighborhood context, institutions and career development. International Journal of Urban and Regional Research, 25(3), 593-608.

Bauder, H. (2002). Neighbourhood effects and cultural exclusion. Urban Studies, 39(1), 85-93.

Bell, P. A., Greene, T. C., Fisher, J. D., \& Baum, A. (1996). Environmental psychology. Orlando, FL: Harcourt Brace College Publishers.

Brodsky, A. E. (1996). Resilient single mothers in risky neighborhoods: Negative psychological sense of community. Journal of Community Psychology, 24(4), 347-363.

Brown, L. A., \& Moore, E. G. (1970). The intra-urban migration process: A perspective. Geografiska Annaler. Series B, Human geography, 52(1), 1-13.

Buck, N. (2001). Identifying neighbourhood effects on social exclusion. Urban Studies, 38(12), 2251-2275.

Clark, W. A. V. (1991). Residential preferences and neighborhood racial segregation: A test of the Schelling segregation model. Demography, 28(1), 1-19.

Clark, W. A. V. (1992). Residential preferences and residential choices in a multiethnic context. Demography, 29(3), 451-466.

Clark, W. A. V., \& Cadwallader, M. (1973). Residential preferences: An alternate view of intraurban space. Environment and Planning, 5(6), 693-703.

Clark, W. A. V., Deurloo, R. C., \& Dieleman, F. M. (2006). Residential mobility and neighbourhood outcomes. Housing Studies, 21(3), 323-342.

Coleman, R. P., \& Neugarten, B. L. (1972). Social status in the city. San Francisco: Jossey-Bass.

Congalton, A. A. (1969). Status and prestige in Australia. Melbourne: Cheshire.

Costa Pinto, T. (2000). Residential contexts of social exclusion: Images and identities. ENHR Conference, Gävle.

Cox, K. (1983). Residential mobility, neighborhood activism and neighborhood problems. Political Geography Quarterly, 2(2), 99-117.

Crump, J. (2002). Deconcentration by demolition: Public housing, poverty, and urban policy. Environment and Planning D: Society and Space, 20, 581-596.

Curtis, R. F., \& Jackson, E. F. (1977). Inequality in American communities. New York: Academic Press.

Dean, J., \& Hastings, A. (2000). Challenging images. Housing estates, stigma and regeneration. Bristol: Policy Press/JRF.

Dietz, R. (2002). The estimation of neighbourhood effects in the social sciences. An interdisciplinary approach. Social Science Research, 31(4), 539-575.

Dowding, K., John, P., Mergoupis, T., \& van Vught, M. (2000). Exit, voice and loyalty: Analytical and empirical developments. European Journal of Political Research, 37, 469-495.

Ellen, I. G., \& Turner, M. A. (1997), Does neighbourhood matter? Assessing recent evidence. Housing Policy Debate, 8(4), 833-866.

Evans, G. W. (1980). Environmental cognition. Psychological Bulletin, 88, 259-287.

Farrell, D. (1983). Exit, voice, loyalty, and neglect as responses to job dissatisfaction: A multidimensional scaling study. Academy of Management Journal, 26, 596-607.

Festinger, L. (1957). A theory of cognitive dissonance. Stanford: Stanford University Press.

Firey, W. (1945). Sentiment and symbolism as ecological variables. American Sociological Review, 10(2), 140-148.

Forrest, R., \& Kearns, A. (2001). Social cohesion, social capital and the neighbourhood. Urban Studies, $38(12), 2125-2143$.

Friedrichs, J. (1998). Do poor neighborhoods make their residents poorer? Context effects of poverty neighborhoods on their residents. In H. Andress (Ed.), Empirical poverty research in a comparative perspective. Aldershot: Ashgate.

Friedrichs, J., \& Blasius, J. (2003). Social norms in distressed neighbourhoods: Testing the Wilson hypothesis. Housing Studies, 18(6), 807-826.

Galster, G. (2001). On the nature of neighbourhood. Urban Studies, 38(12), 2111-2124. 
Galster, G. (2005). Neighborhood mix, social opportunities, and the policy challenges of an increasingly diverse Amsterdam. Amsterdam: AMIDSt.

Galster, G., \& Godfrey, E. (2005). By words and deeds - racial steering by real estate agents in the U.S. in 2000. Journal of American Planning Association, 71(3), 251-268.

Goffman, E. (1963). Stigma: Notes on the management of spoiled identity. New York: Prentice Hall.

Harvey, R. D. (2001). Individual differences in the phenomenological impact of social stigma. Journal of Social Psychology, 14(2), 174-189.

Hastings, A., \& Dean, J. (2003). Challenging images: Tackling stigma through estate regeneration. Policy \& Politics, 31(2), 171-184.

Hastings, A. (2004). Stigma and social housing estates: Beyond pathological explanations. Journal of Housing and the Built Environment, 19(3), 233-254.

Hirschman, A. O. (1970). Exit, voice and loyalty. Massachusetts: Harvard University Press.

Hortulanus, R. P. (1995). Stadsbuurten - bewoners en beheerders in buurten met uiteenlopende reputaties. Den Haag: VUGA.

Hunter, A. (1974). Symbolic communities. The persistence and change of Chicago's local communities. Chicago: The University of Chicago Press.

Kearns, A., \& Parkes, A. (2003). Living in and leaving poor neighbourhood conditions in England. Housing Studies, 18(6), 827-851.

Lee, B. A., Oropesa, R. S., \& Kanan, J. W. (1994). Neighborhood context and residential mobility. Demography, 31(2), 249-270.

Lee, B. A., \& Campbell, K. E. (1997). Common grounds? Urban neighbourhoods as survey respondents see them. Social Science Quarterly, 78(4), 922-936.

Leventhal, T., \& Brooks-Gunn, J. (2000). The neighbourhoods they live in: The effects of neighbourhood residence on child and adolescent outcomes. Psychological Bulletin, 126(2), 309-337.

Logan, J. R., \& Collver, O. A. (1983). Residents' perceptions of suburban community differences. American Sociological Review, 48(3), 428-433.

Lu, M. (1998). Analyzing migration decisionmaking: Relationships between residential satisfaction, mobility intentions, and moving behavior. Environment and Planning A, 30(8), 1473-1495.

Lyons, W. E., \& Lowery, D. (1986). The organization of political space and citizen responses to dissatisfaction in urban communities: An integrative model. The Journal of Politics, 48(2), 321-346.

Manski, C. (1993). Identification of endogenous social effects: The reflection problem. Review of Economic Studies, 60(3), 531-542.

Marcuse, P. (1993). What's so new about divided cities? International Journal of Urban and Regional Research, 17(3), 355-365.

Marshall, G. (1998). Oxford dictionary of sociology. Oxford: Oxford University Press.

Mazanti, B., \& Pløger, J. (2003). Community planning - from politicised places to lived spaces. Journal of Housing and the Built Environment, 18(3), 309-327.

Musterd, S., Ostendorf, W., \& de Vos, S. (2003). Neighbourhood effects and social mobility: A Longitudinal analysis. Housing Studies, 18(6), 877-892.

O'Donnell, G. (1986). On the fruitful convergences of Hirschman's exit, voice, and loyalty and shifting involvements: Reflections from the recent Argentine experience. In A. Foxley, M. McPherson, \& G. O'Donnell (Eds.), Development, democracy and the art of trespassing: Essays in honor of Albert Hirschman. Notre Dame: Notre Dame Press.

Orbell, J., \& Uno, T. (1972). A theory of neighborhood problem solving: Political action vs. residential mobility. American Political Science Review, 66(2), 471-489.

Overman, H. G. (2002). Neighbourhood effects in large and small neighbourhoods. Urban Studies, 39(1), 117-130.

Oxford Dictionary. (2004). Reputation [online]. [Quoted 10 december]. Available on World Wide Web: $<$ http://www.askoxford.com/dictionaries/?view=uk>.

Purdy, S. (2003). 'Ripped Off' 'by the system: Housing policy, poverty, and territorial stigmatization in Regent Park Housing Project, 1951-1991 [online]. [Quoted 25 january] Available on World Wide Web: <http://www.historycooperative.org/journals/llt/52/purdy.html>.

Putnam, R. D. (2000). Bowling alone. New York: Simon \& Schuster.

Rijpers, B., \& Smeets, J. (1998). Housing challenge: Managing neighbourhood image. Cardiff: ENHR Cardiff.

Rose, G. (1995). Place and identity: A sense of place. In D. Massey \& P. Jess (Eds.), A place in the World? Places, cultures and globalization. Oxford: The Open University. 
Rossi, P. H. (1955). Why families move. A study in the social psychology of urban residential mobility. Glencoe: The Free Press.

Rusbult, C. E., Zembrodt, I. M., \& Gunn, L. K. (1982). Exit, voice, loyalty, and neglect: Responses to dissatisfaction in romantic involvements. Journal of Personality and Social Psychology, 43, 1230-1242.

Sampson, R. J., Morenoff, J. D., \& Gannon-Rowley, T. (2002). Assessing "Neighborhood effects": Social processes and new directions in research. Annual Review of Sociology, 28, 443-478.

Semyonov, M., \& Kraus, V. (1982). The social hierarchies of communities and neighborhoods. Social Science Quarterly, 63(4), 780-789.

Suttles, G. D. (1968). The social order of the slum. Ethnicity and territory in the inner city. Chicago: The University of Chicago Press.

Suttles, G. D. (1972). The social construction of communities. Chicago: The University of Chicago Press.

Taylor, M. (1998). Combating the social exclusion of housing estates. Housing Studies 13(6), 819-832.

Tsfati, Y., \& Cohen, J. (2003). On the effect of the "Third-person effect'": Perceived influence of media coverage and residential mobility intentions. Journal of Communication, 53, 711-727.

Van der Horst, H., Kullberg, J., \& Deben, L. (2001). Wat wijken maakt. Delft: DGVH/NETHUR.

Van Kempen, E. (1997). Poverty pockets and life chances. American Behavioral Scientist, 41(3), 430-449.

Van Vught, M., Dowding, K., John, P., \& van Dijk, E. (2003). The exit of residential mobility or the voice of political action? Strategies for problem solving in residential communities. Journal of Applied Social Psychology, 33(2), 321-338.

Wacquant, L. J. D. (1993). Urban outcasts: Stigma and division in the black American ghetto and the French periphery. International Journal of Urban and Regional Research, 17(3), 366-383.

Wacquant, L. D. J. (1998). Negative social captial: State breakdown and social destitution in America's urban core. Netherlands Journal of Housing and the Built Environment, 13(1), 25-40.

Wacquant, L. J. D. (2004). Ghetto. In N. J. Smelser \& P. B. Baltes (Eds.), International encyclopedia of the social and behavioral sciences. London: Pergamon Press.

Warner, W. L., Meeber, M., et al. (1960). Social class in America: A manual of procedure for the measurement of social status. New York: Harper and Row.

Wilson, W. J. (1987). The truly disadvantaged; the inner city, the underclass and public policy. Chicago: The University of Chicago Press.

Wilson, W. J. (1996). When work disappears. Chicago: The University of Chicago Press.

Wakefield, S., \& McMullan, C. (2005). Healing in places of decline: (Re)imaging everyday landscapes in Hamilton, Ontario. Health \& Place, 11, 299-312.

Wyly, E. K. (2002). Mortgaged metropolis: Evolving urban geographies of residential lending. Urban Geography, 23(1), 3-30. 